\section{Monitoring Foreign Protein Expression under Baculovirus p10 and polh Promoters in Insect Larvae}

BioTechniques 32:986-992 (May 2002)

The baculovirus expression system is based on replacing the gene of either the major matrix protein of the NPV occlusion body, polyhedrin (8), or the 10$\mathrm{kDa}$ fibrous polypeptide, p10 (19), with the gene of interest. These proteins have been shown to be nonessential for viral infection and replication in cell culture that facilitates virus maintenance (17), and they are expressed at very high levels $(30 \%-50 \%$ of total protein) during the very late stages of infection. Therefore, these genes can be replaced with desired genes so that the desired protein is made in correct functional form and often in abundance at the time the polyhedrin or $\mathrm{p} 10$ proteins would otherwise be expressed. This baculovirus system has many advantages such as correct functionality of the foreign proteins $(10,12)$, high expression level for many proteins (10), possibility of post-translational modification (e.g., glycosylation) (1), capacity for large DNA insertions (9), capacity for the expression of unspliced genes, simplicity (e.g., expression kits are commercially available), and simultaneous expression of multiple genes. There is also no requirement for transformed cells, and the system is non-pathogenic to vertebrates and plants $(11,13)$.

The larvae expression system currently entails synchronous infection with recombinant virus, either by feeding per Os (virus pre-absorbed on diet) or by injecting into the cuticle (9). As the larvae grow, the virus replicates. After three or four days, the larvae are harvested, and extracts are prepared for protein purification (2). Alternatively, unharvested larvae die, and subsequent melanization results in loss of recombinant product. The larvae expression system presently relies on the synchronous infection and synchronous harvesting when the recombinant protein is at a maximum. In our previous work, we demonstrated that GFP [specifically a UV variant, GFPuv (7)] could be used as an effective indicator of product level (2). That is, larvae that produced GFP from the polyhedrin promoter were easily distinguished from uninfected larvae upon simple illumination with UV light. Moreover, the level of fluorescence was linear with the quantity of GFP contained within the larvae. A unique attribute of GFP as a protein marker is that it requires no co-factors or staining for fluorescence, and the fluorescence is readily visible from outside the cells (6). We also demonstrated that human interleukin-2 (hIL-2), which was expressed as a fusion protein with GFP, appeared almost simultaneously with GFP fluorescence, thereby facilitating determination of the best harvest time. In similar work with another recombinant protein product, chloramphenicol acetyltransferase, GFP fluorescence tracked the product level (data not shown), suggesting general applicability for this technique.

In the present work, we have monitored and compared the expression of foreign hIL-2 protein under two different promoters, p10 and polyhedrin, in an insect larvae expression system using the GFP fusion technique. Our gene fusions consist of from the N- to C-terminus of a histidine affinity ligand [(His) $)_{6}$, the $g f p_{u v}$ gene, an enterokinase cleavage site, followed by the gene for the protein-of-interest, hil-2. The model product here is hIL-2, which is a power- ful immunoregulatory lymphokine that has been evaluated as a therapeutic agent in the treatment of cancer $(14,16)$.

The recombinant baculoviruses, vP10-GFPuv/hIL2 and $v$ P10-hIL2, were obtained by co-transfecting pAcUWHGFPuv/hIL2 and pAcUWH-hIL2 (4) with wild-type AcNPV DNA (linearized AcUW1.lacZ baculovirus DNA; BD Biosciences, San Jose, CA, USA) into Sf9 insect cells (18). The recombinant baculoviruses, vPH-GFPuv/hIL2 and $v \mathrm{PH}-\mathrm{hIL} 2$, were obtained by co-transfecting $\mathrm{pBBH}-\mathrm{GFPuv} / \mathrm{hIL} 2$ and $\mathrm{pBBH}-$ hIL2 (5) with wild-type AcNPV DNA (Bac-N-Blue ${ }^{\mathrm{TM}}$ baculovirus DNA; Invitrogen, Carlsbad, CA, USA) into $S f 9$ insect cells. The pAcUWH-GFPuv/hIL2 (under p10 promoter; see Figure 1A) and $\mathrm{pBBH}-\mathrm{GFPuv} / \mathrm{hIL2}$ (under polyhedrin promoter; see Figure 1C) vectors contained the histidine affinity ligand on the N-terminus of the $g f p_{u v}$ gene and the enterokinase cleavage site between the $g f p_{u v}$ and hil-2 genes. The pAcUWHhIL2 (under p10 promoter; see Figure 1B) and pBBH-hIL2 (under polyhedrin promoter; see Figure 1D) vectors are the same, minus the $g f p_{u v}$ gene. Both are polyhedrin minus. Recombinant virus stocks were propagated in $S f 9$ cells in tissue culture flasks at $27^{\circ} \mathrm{C}$. The viruses were titered by end-point dilution (13). In the case of $v$ P10-GFPuv/hIL2 and vPH-GFPuv/hIL2, we were able to titer them easily by seeing green fluorescence using simple fluorescent microscopy or a UV transilluminator (3).

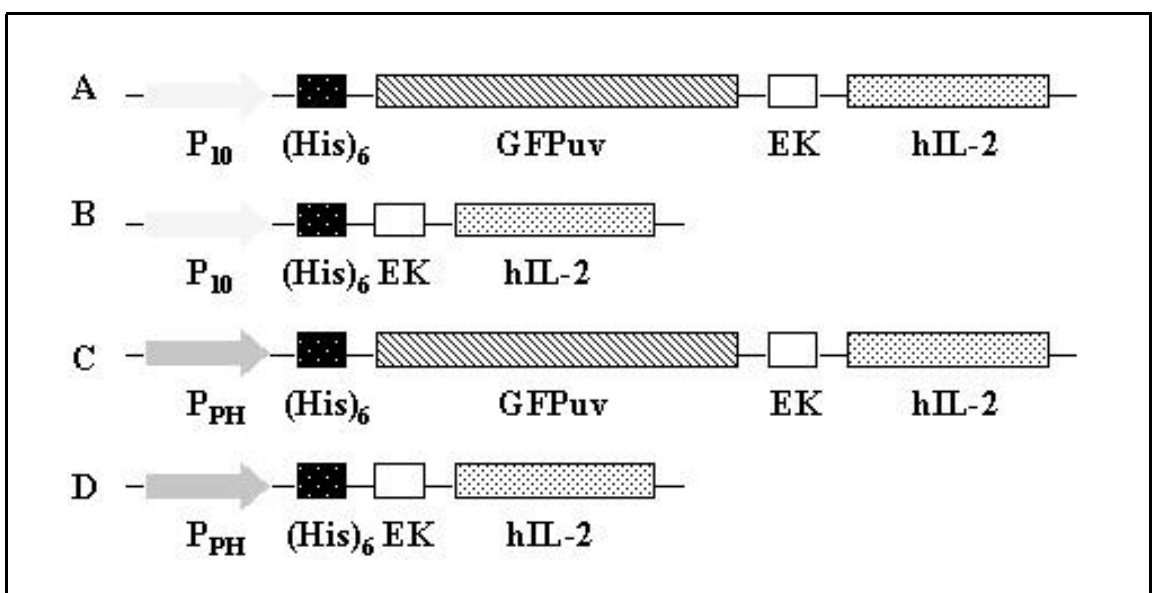

Figure 1. Schematics of recombinant baculoviruses. Structure of the GFPuv/hIL-2 fusion (A and C) and hIL-2 single gene (B and D) containing histidine affinity ligand (His) $)_{6}$ and enterokinase (EK) cleavage site expressed by the $\mathrm{p} 10\left(\mathrm{P}_{10}\right)(\mathrm{A}$ and $\mathrm{B})$ and polyhedrin $\left(\mathrm{P}_{\mathrm{PH}}\right)(\mathrm{C}$ and $\mathrm{D})$ promoter in baculovirusinfected larvae. 
Trichoplusia ni (cabbage looper) insect larvae were used. The eggs were hatched in Styrofoam cups containing solid food (all from Entopath, Easton, PA, USA) at $30^{\circ} \mathrm{C}$, and the fourth instar larvae were used for infection experiments (15). The recombinant baculoviruses were spread on the media at various viruses loading (pfu/cup), which were obtained pre-made in Styrofoam cups. The cups were covered and allowed to stand for $1 \mathrm{~h}$ for the virus to be completely absorbed by the media.
The fourth instar larvae (four days after hatching) were then placed into the cups (15 larvae/cup). The cups were then inverted, and the larvae were allowed to feed on the infected food at $30^{\circ} \mathrm{C}$. The cups were inverted so that the larvae fed from the top (bottom of cup) and the fecal matter dropped on to the lid to be discarded daily.

For each sample, five infected larvae were collected and frozen at $-70^{\circ} \mathrm{C}$ until they were ready for cell mass, total protein, GFPuv, and hIL-2. The frozen

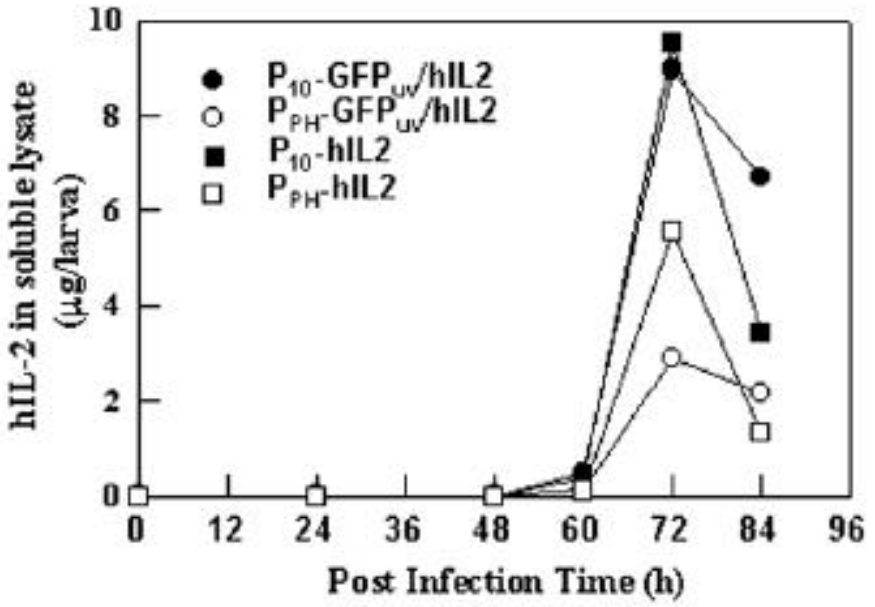

Figure 2. Time course of hIL-2 mass in soluble lysate from baculovirus-infected insect larvae. Larvae were infected with the recombinant baculoviruses $v$ P10-GFPuv/hIL2, $v$ P10-hIL2, $v$ PH-GFPuv/hIL2, and $v$ PH-hIL2 of $5 \times 10^{7} \mathrm{pfu} / \mathrm{cup}$, and grown at $30^{\circ} \mathrm{C}$. Each data point represents five larvae; the data are reported on a per larva basis. Quantification of hIL-2 was performed by Western blot analysis.

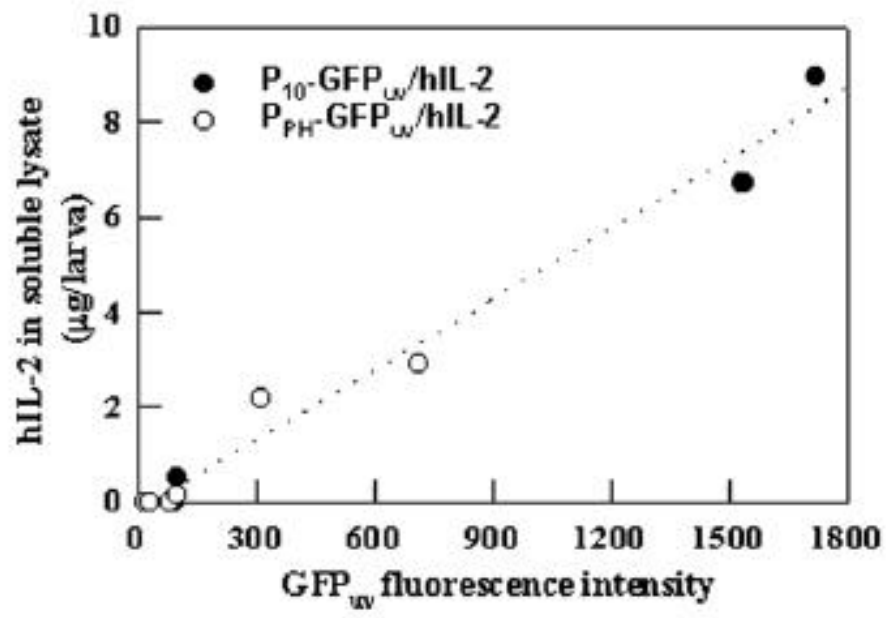

Figure 3. Correlation between GFPuv fluorescence intensity and hIL-2 mass. Linearity was established over the full range of observed fluorescence $(n=5)$. larvae were thawed and homogenized in PBS containing $60 \mathrm{mM}$ DTT and $0.5 \%$ Triton $^{\circledR} \mathrm{X}-100$ at $\mathrm{pH}$ 7.0. The samples prepared for recombinant protein assay also contained the following protease inhibitors: $1.1 \mathrm{mM}$ PMSF, 1 $\mathrm{mM}$ EDTA, and $0.2 \mathrm{mg} / \mathrm{mL}$ benzamidine. We had previously determined that this cocktail of protease inhibitors was effective in minimizing proteolysis during purification (15). The homogenate was then centrifuged at $4^{\circ} \mathrm{C}$ to remove large debris. We used this supernatant as a soluble lysate.

The total protein assay was performed using a protein assay kit (BioRad Laboratories, Hercules, CA, USA) with BSA as a standard. GFPuv fluorescence intensity was measured using a fluorescence spectrometer (LS-3B; Perkin-Elmer, Beaconsfield, Buckinghamshire, UK) at an excitation wavelength of $395 \mathrm{~nm}$ and emission at $509 \mathrm{~nm}$.

The quantities of hIL-2 were determined using pure recombinant hIL-2 of 0.025 and $0.05 \mu \mathrm{g}$ from $E$. coli (Invitrogen) as a calibration standard on Western blots. The nitrocellulose membrane was probed with 1:2000 dilution of polyclonal anti-rhIL-2 antibody (CYTImmune Science, College Park, MD, USA). It was detected with 1:5000 dilution of goat anti-rabbit IgG conjugated to alkaline phosphatase (Kirkegaard \& Perry Laboratories, Gaithersburg, MD, USA) and 5-bromo-4-chloro-3-indolyl phosphate/nitro blue tetrazolium (BCIP/NBT) color development reagent (Sigma, St. Louis, MO, USA). The stained membranes were scanned (Umax Computer, Fremont, CA, USA), and the digitized images were analyzed by NIH image software (National Institutes of Health).

The time courses of GFPuv/hIL-2 fusion and hIL-2 single protein under p10 or polyhedrin (polh) promoter are depicted in Figure 2. To quantify the GFPuv fluorescence and hIL-2 mass, we homogenized the larvae in buffer, centrifuged, and saved the supernatants as soluble lysates. Quantification of hIL-2 mass was performed by densitometric scanning of Western blots employing polyclonal anti-hIL-2 antibody. In both promoter systems, the hIL-2 masses in the soluble lysates were insignificant until $60 \mathrm{~h}$ after infection but increased rapidly to a maximum at $72 \mathrm{~h}$ 
Table 1. Summary of hIL-2 Yields in Larvae under p10 and Polyhedrin Promoters

\begin{tabular}{|c|c|c|c|c|}
\hline & vP10-GFPuv/hIL2 & uPH-GFPuv/hIL2 & vP10-hIL2 & vPH-hIL2 \\
\hline Infection & $5 \times 10^{7} \mathrm{pfu} / \mathrm{cup}$ & $5 \times 10^{7} \mathrm{pfu} / \mathrm{cup}$ & $5 \times 10^{7} \mathrm{pfu} / \mathrm{cup}$ & $5 \times 10^{7} \mathrm{pfu} / \mathrm{cup}$ \\
\hline Average larva mass ${ }^{a}$ & $0.35 \mathrm{~g}$ & $0.33 \mathrm{~g}$ & $0.34 \mathrm{~g}$ & $0.36 \mathrm{~g}$ \\
\hline Total soluble proteina,b & $3.6 \mathrm{mg} / \mathrm{larva}$ & $7.6 \mathrm{mg} / \mathrm{larva}$ & $4.2 \mathrm{mg} / \mathrm{larva}$ & $9.3 \mathrm{mg} / \mathrm{larva}$ \\
\hline Total hIL-2 yielda,b & $45.0 \mu \mathrm{g} / \mathrm{larva}$ & $21.3 \mu \mathrm{g} /$ larva & $73.1 \mu \mathrm{g} / \mathrm{larva}$ & $19.8 \mu \mathrm{g} / \mathrm{larva}$ \\
\hline Soluble lysate hIL-2 yielda & $9.0 \mu \mathrm{g} / \mathrm{larva}$ & $2.9 \mu \mathrm{g} / \mathrm{larva}$ & $9.5 \mu \mathrm{g} / \mathrm{larva}$ & $5.8 \mu \mathrm{g} / \mathrm{larva}$ \\
\hline $\begin{array}{l}\text { Total soluble hIL-2/mg total } \\
\text { soluble proteina }\end{array}$ & $2.52 \mu \mathrm{g} / \mathrm{mg}-\mathrm{tp}$ & $0.38 \mu \mathrm{g} / \mathrm{mg}-\mathrm{tp}$ & $2.28 \mu \mathrm{g} / \mathrm{mg}-\mathrm{tp}$ & $0.60 \mu \mathrm{g} / \mathrm{mg}-\mathrm{tp}$ \\
\hline $\begin{array}{l}\text { Percent of soluble product } \\
\text { from total producta }\end{array}$ & $19.7 \%$ & $13.6 \%$ & $12.6 \%$ & $28.1 \%$ \\
\hline \multicolumn{5}{|c|}{$\begin{array}{l}\text { a at maximum yield hIL-2 yield } \\
\text { bbased on total cell (soluble lysate + insoluble pellet) } \\
\text { tp, total protein }\end{array}$} \\
\hline
\end{tabular}

after infection. These then rapidly decreased because of proteolysis. Interestingly, the same expression profiles were shown in both p10 and polyhedrin promoter systems regardless of protein (fusion or native). When we compare expression levels of $\mathrm{p} 10$ and polyhedrin promoter systems using the same virus loading, the p10 promoter system showed higher expression levels in both the fusion and single protein systems. Note that the infection efficiency might have been variable because the recom binant baculoviruses did not form occluded virions that otherwise establish efficient and consistent infection of larva by an oral route (12).

Most importantly, however, the GFPuv fluorescence intensities closely tracked the hIL-2 profiles in both promoter systems. As shown in Figure 3, a linear correlation was obtained between GFPuv fluorescence intensity and hIL-2 mass regardless of promoter. These results are suggestive that GFP fusions can be monitored by green fluorescence using either promoter system. Based on this correlation, the in vivo quantification of hIL-2 was made possible by simple measurement of GFPuv fluorescence intensity, obviating the need for laborious Western blot analysis and ELISAs. Similarly, we have recently performed analyses for the detection of chloramphenicol acetyltransferase in larvae, wherein the level of fluorescence was directly related to the quantity of the fusion partner (data not shown). This suggests general applicability for monitoring recombinant protein production in larvae by GFP fluorescence.

In general, the total soluble protein was higher for the polyhedrin promoter system at maximum hIL-2, but the p10 promoter system showed higher foreign protein yields (see Table 1). Further, the hIL-2 solubility appears to be higher when expressed without the GFP fusion partner. This represents a disadvantage for employing a GFP fusion (Table 1).

However, as shown Figure 2, the degradation of hIL-2 $72 \mathrm{~h}$ after infection was much less in the fusion structures of both p10 and polyhedrin promoter systems. This suggests that hIL-2 in the fusion structure was protected from proteolysis; thus, we can obtain higher yield of hIL-2 after harvesting. In general, the harvesting of larvae that produce a maximum amount of foreign protein is not a simple undertaking, even though we use GFP as a harvest marker (2), because there are many factors affecting the harvest, such as virus loading, culture temperature, larval instar, infection efficiency depending on viruses, etc. Therefore, we cannot a priori say the optimal harvest time is three days after infection. However, using the GFP as a fusion and harvest marker, one can harvest the larvae that, given the other environmental/cellular factors, are producing the hIL-2 fusion protein. Further, since the stability of hIL-2 was im proved in the fusion, we can obtain a higher yield of hIL-2 after harvesting.

\section{REFERENCES}

1.Cameron, I.R. and D.H.L. Bishop. 1989. Insect cell culture technology in baculovirus expression system. TIBTECH 7:66-70.

2.Cha, H.J., M.Q. Pham, G. Rao, and W.E. Bentley. 1997. Expression of green fluorescent protein in insect larvae and its application for foreign protein production. Biotechnol. Bioeng. 56:239-247.

3.Cha, H.J., T. Gotoh, and W.E. Bentley. 1997. Simplification of titer determination for recombinant baculovirus by green fluorescent protein marker. BioTechniques 23:782-786.

4.Cha, H.J., N.G. Dalal, M.Q. Pham, V.N. Vakharia, G. Rao, and W.E. Bentley. 1999. Insect larval expression process is optimized by generating fusions with green fluorescent protein. Biotechnol. Bioeng. 65:316-324.

5.Cha, H.J., N.G. Dalal, V.N. Vakharia, and W.E. Bentley. 1999. Expression of human interleukin-2 as a fusion with green fluorescent protein in suspended $\mathrm{Sf}-9$ insect cells. J. Biotechnol. 69:9-17.

6.Chalfie, M., Y. Tu, G. Euskirchen, W.W. Ward, and D.C. Prasher. 1994. Green fluorescent protein as a marker for gene expression. Science 263:802-805.

7.Crameri, A., E.A. Whitehorn, E. Tate, and W.P.C.Stemmer. 1996. Improved green fluorescent protein by molecular evolution using DNA shuffling. Nat. Biotechnol. 14:315-319.

8.Harrap, K. 1972. The structure of nuclear polyhedrosis viruses. I. The inclusion body. Virology 50:114-123.

9.King, L.A. and R.D. Possee. 1992. The Baculovirus Expression System: A Laboratory Manual. Chapman and Hall, New York.

10.Luckow, V.A. and M.D. Summers. 1988. Trends in the development of baculovirus expression vectors. Biotechnology 6:47-55.

11.Miller, L.K. 1981. A virus vector for genetic engineering in invertebrates, p. 203-224. In N. Panopoulos (Ed.), Genetic Engineering in the Plant Sciences. Praeger, New York.

12.Miller, L.K. 1988. Baculoviruses as gene expression vectors. Annu. Rev. Microbiol. 42:177-199. 
13.O'Reilly, D.R., L.K. Miller, and V.A. Luckow. 1992. Baculovirus Expression Vectors: A Laboratory Manual. Freeman, New York.

14.Paciotti, G.F. and L. Tamarkin. 1988. Interleukin-2 differentially affects the proliferation of a hormone-dependent and a hormone-independent human breast cancer cell line in vitro and in vivo. Anticancer Res. 8:1233-1239.

15.Pham, M.Q., S. Naggie, M. Wier, H.J. Cha, and W.E. Bentley. 1999. Human interleukin2 production in insect (Trichoplusia ni) larvae: the effects and partial control of proteolysis. Biotechnol. Bioeng. 60:165-172.

16. Rosenburg, S.A., E.A. Grimm, M. McGrogan, M. Doyle, E. Kawasaki, K. Koghs, and D.F. Mark. 1984. Lymophokine activated T cells in the treatment of cancer. Science 223:1412-1415.

17.Smith, G.E., M.J. Fraser, and M.D. Sum mers. 1983. Molecular engineering of the $\mathrm{Au}$ tographa califonica nuclear polyhedrosis virus genome: deletion mutations within the polyhedrin gene. J. Virol. 46:584-593.

18.Summers, M.D. and G.E. Smith. 1987. A manual of methods for baculovirus vectors and insect cell culture procedure. Texas Agricultural Experiment Station Bulletin No. 1555.

19.van der Wilk, F., J.W.M. van Lent, and J.M. Vlak. 1987. Immunogold detection of polyhedrin p10 and viron antigens in Autographa califonica nuclear polyhedrosis virusinfected Spodoptera frugiperda cells. J. Gen. Virol. 68:2615-2624.
Address correspondence to Dr. William E. Bentley, Department of Chemical Engineering, University of Maryland, College Park, MD 20742, USA. e-mail: bentley@ eng.umd.edu

Received 15 October 2001; accepted 19 February 2002.

H.J. Cha, N.G. Dalal, M.-Q. Pham, S.F. Kramer, V.N. Vakharia, and W.E. Bentley University of Maryland College Park, MD, USA

For reprints of this or any other article, contact Reprints@BioTechniques.com

\section{Increased Efficiency of Cloning Large DNA Fragments Using a Lower Copy Number Plasmid}

BioTechniques 32:992-998 (May 2002)

The advent of recombinant DNA technology has revolutionized biological and genetic research $(9,10)$. These technologies have allowed us to perform previously unthinkable tasks, such as the sequencing of the human genome and the deletion of a gene of interest in animal models $(6,14,21)$. Most of the commonly used cloning vectors are derived from bacterial plasmids, which are self-replicating extrachromosomal DNA molecules found in virtually all bacterial species $(1,9)$. Most plasmids are double-stranded, circular DNA molecules, and their replication is coordinated with that of the bacterial host $(16,19)$. Plasmid vectors used for molecular cloning are primarily derived from $E$. coli plasmids. These vectors possess three common features: a replicator, at least one antibiotic selectable marker, and a multiple cloning site (MCS). The replicator is a stretch of DNA sequence that contains the origin of replication (ori) and encodes the RNAs and proteins required for plasmid replication in host cells. Although the mechanisms underlying plasmid copy number control are still the subject of extensive investigations, it is believed that the replicator may play a pivotal role in determining the copy number of a given plasmid in different host cells $(11,20)$. Most cloning vectors contain a replicator derived from the prototypic ColE1 origin. Although both pBR322 and pUC19 plasmid vectors contain similar replicators from the ColE1-related pMB1 $(4,13)$, subtle changes in the replicators render them significantly different in their ability to maintain their copy number in host cells. As a result, in most host cells, the pBR322 vector is maintained at 100-300 copies per cell, whereas the pSL301plasmid with the pUC19 replicator contains 1000-3000 copies per cell $(3,5,22,25,26)$.

Although recombinant DNA technology has been established for more than two decades, subcloning large DNA fragments remains a rather challenging maneuver $(15,18)$. Our previous experience with the construction of the AdEasy ${ }^{\mathrm{TM}}$ (www.coloncancer.org/ adeasy.htm) and other large vectors suggested that the cloning efficiency of large DNA molecules might be affected by the copy number of a given vector. Higher cloning efficiency was seemingly associated with the use of a lower copy number vector (12). This phenomenon was particularly true when larger inserts (e.g., >3 kb) or larger destination constructs (e.g., >10 kb) were involved. In this report, we sought to test the above observations using a more definitive approach.

To ensure that a lower copy number vector was structurally comparable to a high copy number vector (i.e., pSL301; Invitrogen, Carlsbad, CA, USA), we engineered the pMOLUC vector that contains a pBR322-derived replicator. Specifically, a 507-bp fragment containing the MCS was PCR-amplified from a pSL301 vector using the M13 forward and M13 reverse primers, $5^{\prime}$-GTAAA ACGACGGCCAGT-3' and 5'-GGAA 